$4^{\text {th }}$ International Meeting on Calcitonin Gene-Related Peptide (CGRP)

TheScientificWorld (2001) 1(S1), 28

ISSN 1532-2246; DOI 10.1100/tsw.2001.422

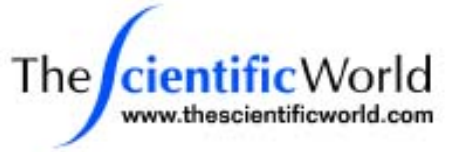

\title{
PHARMACOLOGICAL DIFFERENCES BETWEEN HUMAN AND RAT CGRP RECEPTORS ARE DETERMINED BY RAMP1
}

\author{
S. Kane ${ }^{1}$, J. Mallee ${ }^{1}$, C. Salvatore ${ }^{1}$, B. LeBourdelles ${ }^{2}$, and K. Koblan ${ }^{1}$ \\ ${ }^{1}$ Merck Research Laboratories, Department of Pharmacology, West Point, PA 19486; ${ }^{2}$ Merck \\ Research Laboratories, Neuroscience Research Center, Harlow, Essex CM20 U.K.
}

\section{INTRODUCTION}

Several small molecule CGRP receptor antagonists have now been reported and their effects profiled in a variety of in vivo assays. Of particular interest is the observation that some antagonists display marked species selectivity. Doods and coworkers[1] reported that BIBN4096BS exhibited 200-fold higher affinity for human and marmoset CGRP receptors, than for receptors from rat, dog, guinea pig and rabbit. In addition, Edvinsson and colleagues[2] reported that compound 1 was a significantly more potent antagonist on human cerebral arteries than on guinea pig arteries. In the present study, we sought to identify the molecular basis for this profound species selectivity.

\section{METHODS}

Hybrid CGRP receptors were constructed by cotransfection of either human or rat CRLR with human or rat RAMP1 in 293 EBNA cells. Chimeric RAMP1 constructs were prepared by replacing the first 66 amino acids (chimera 1) or first 112 amino acids (chimera 2) of rat RAMP1 with the corresponding human sequence. Human or rat CRLR was cotransfected with either the native or chimeric RAMP1. Membranes were prepared and employed for competition binding and deglycosylation experiments.

\section{RESULTS}

The IC $_{50} \mathrm{~S}$ of BIBN4096BS and compound 1 for displacement of ${ }^{125}$ I-hCGRP from hCRLR/rRAMP1 membranes were similar to that for rCRLR/rRAMP1. The affinity of CGRP P-37 $_{8}$ was unaffected by the species origin of RAMP1. The IC F0 $_{5}$ of BIBN4096BS and compound 1 for rCRLR/chimera1 were similar to that for rCRLR/rRAMP1, whereas rCRLR/chimera 2 yielded $\mathrm{IC}_{50} \mathrm{~S}$ similar to that of rCRLR/hRAMP1.

Coexpression of rCRLR with either human or rat RAMP1 resulted in the production of a mature glycoprotein.

\section{CONCLUSION}

The high affinity of BIBN4096BS and compound 1 for hCRLR/hRAMP1 was dictated strictly by hRAMP1. The region between amino acids 66-112 was critical for determining the pharmacology of these small molecule antagonists. The exact molecular mechanisms by which RAMP1 modulates antagonist binding sites remain to be elucidated.

\section{REFERENCES}

1. Doods, H., Hallermayer, G., Wu, D., Entzeroth, M., Rudolf, K., Engel, W., and 
Eberlein, W. (2000) Pharmacological profile of BIBN4096BS, the first selective small molecule CGRP antagonist. Br. J. Pharmacol. 129, 420-423.

2. $\quad$ Edvinsson, L., Sams, A., Jansen-Olesen, I., Tajti, J., Kane, S.A., Rutledge, R.Z., Koblan, K.S., Hill, R.G., and Longmore, J. (2001) Characterisation of the effects of a non-peptide CGRP receptor anagonist in SK-N-MC cells and isolated human cerebral arteries. Eur. J. Pharmacol. 415, 39-44. 

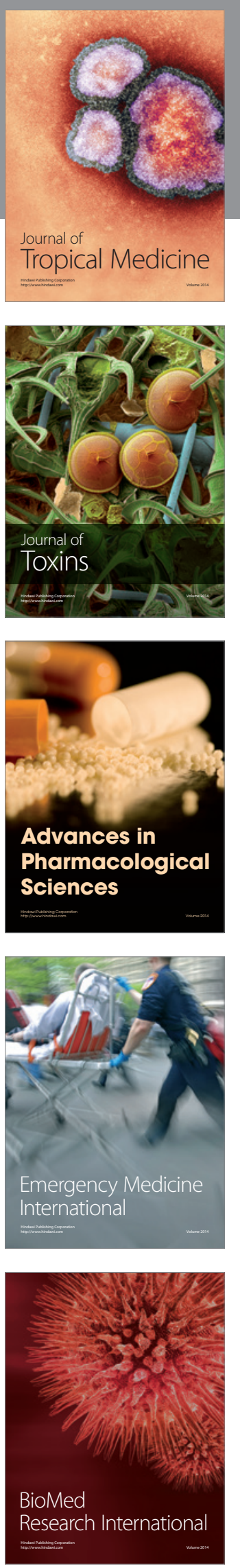
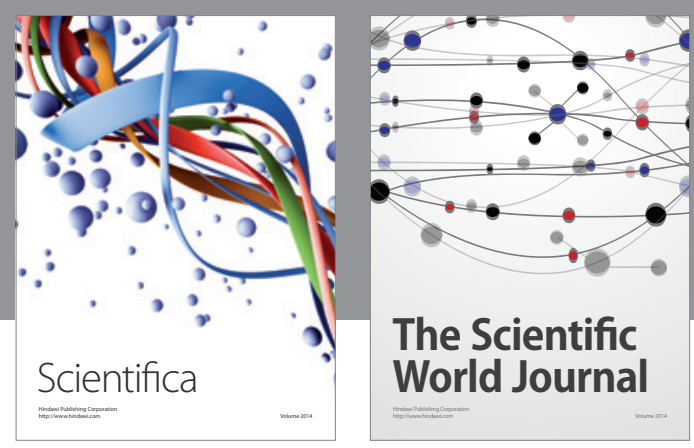

The Scientific World Journal
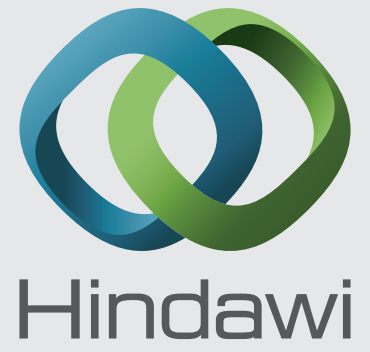

Submit your manuscripts at

http://www.hindawi.com
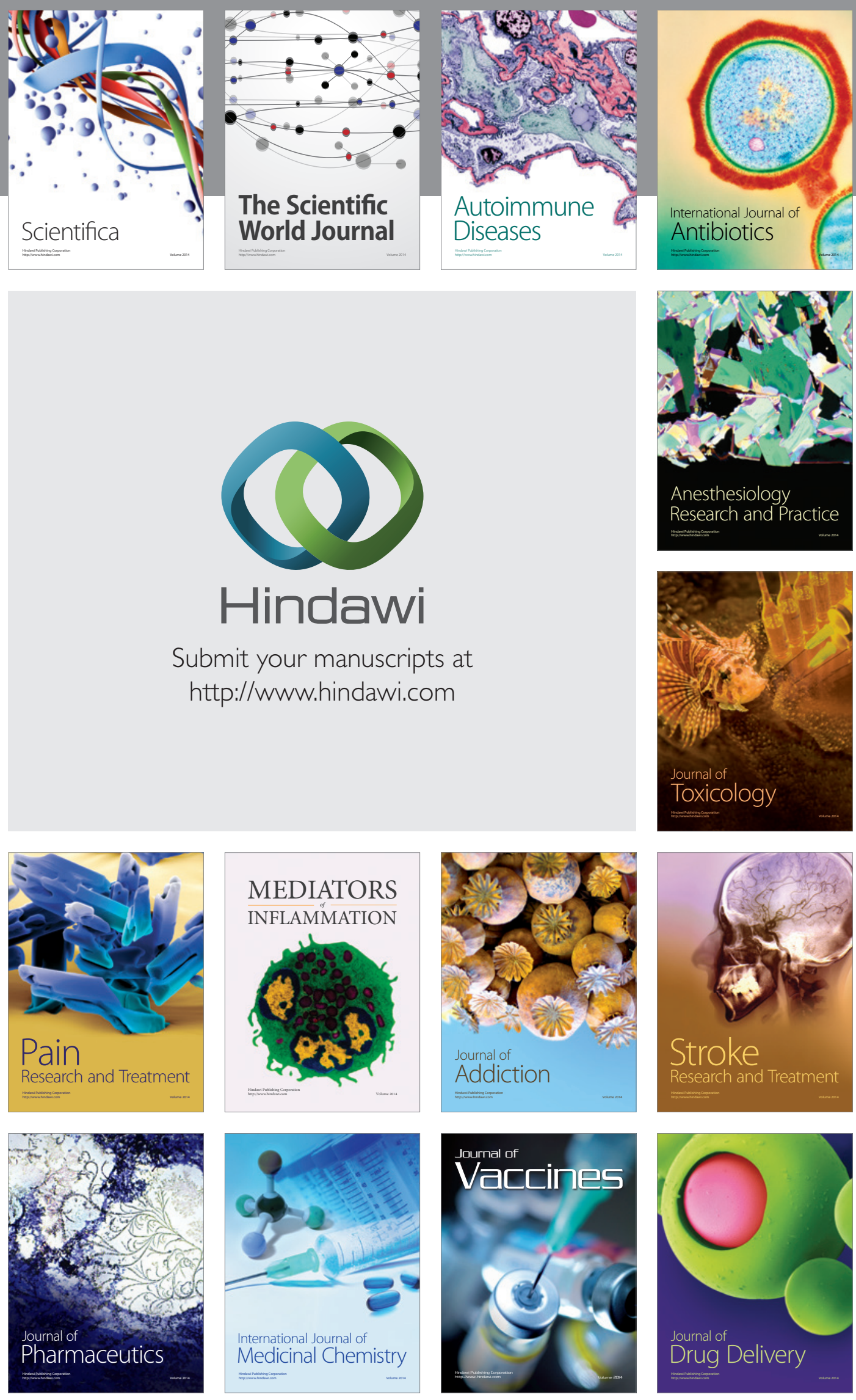